23

\title{
Orange dye Removal Efficiency by Few-layer Graphene: an Investigation by UV-Vis Spectroscopy*
}

\author{
(c) Hamid Motahari, Hoorieh Shaterian Mohammadi, and Abbas Behjat \\ Atomic and Molecular Group, Department of Physics, Faculty of Science, Yazd University, \\ 89195-741 Yazd, Iran \\ e-mail: H.Motahari@Yazd.ac.ir
}

Received June 26, 2021

Revised June 26, 2021

Accepted September 01, 2021

Nowadays, few-layer graphene (FLG) has been introduced as a new type of adsorbent. In this research, the orange dyes including, methyl orange (MO) as an industrial dye and the soft drink orange dye (orange Fanta soda) as a food dye, have been removed by FLG adsorbent. In all steps, UV-Vis spectroscopy as a valuable and fast method has been applied. The optical absorption coefficient has been decreased from 0.9 to less than 0.2 by FLG adsorbent for $50 \mathrm{ppm}$ MO dye solution. Therefore, the MO solution with $50 \mathrm{ppm}$ concentration converts to about $10 \mathrm{ppm}$ output solution using $0.05 \mathrm{~g}$ of FLG adsorbent in a few minutes. It is about $80 \%$ adsorption dye removal efficiency. Also, MO dye removals have been performed in the range of $10 \mathrm{ppm}$ to $500 \mathrm{ppm}$ concentrations, but as the concentration of the solution increases, the dye adsorption ability of FLG decreases. The maximum efficient and optimum MO dye concentrations are about $100 \mathrm{ppm}$ and $50 \mathrm{ppm}$, respectively, due to $0.05 \mathrm{~g}$ FLG adsorbent. It has been completely saturated at about $500 \mathrm{ppm}$ concentration MO dye solution. Also, it has been observed that, for $50 \mathrm{ppm} \mathrm{MO}$ dye solution, increasing the amount of mass adsorbent from $0.05 \mathrm{~g}$ to $0.25 \mathrm{~g}$ can cause the output MO concentration to decrease from $10 \mathrm{ppm}$ to $3 \mathrm{ppm}$. It has been revealed that about $94 \%$ of MO dye can remove by $0.25 \mathrm{~g}$ FLG adsorbent. The contact time due to $94 \% \mathrm{MO}$ removal process is less than 5 minutes. Therefore, only by $0.25 \mathrm{~g}$ of FLG adsorbent we can purify wastewater containing $50 \mathrm{ppm}$ MO dye to less than 3 ppm dye concentration, at less than a few minutes. Finally, the FLG glass tube filter can remove more than $90 \%$ food orange dye in less than 90 seconds for $50 \mathrm{ml}$ of soft drink solution. Therefore, the FLG tube filtration process is so fast, easy, and high efficient.

Keywords: adsorption, Few-Layer Graphene, methyl orange, UV-Vis spectroscopy, orange dye.

\footnotetext{
* Полный текст статьи опубликован в „Optics and Spectroscopy“ 2022 V. 130. N 02.
} 